\title{
Research Progress of Wastewater Treatment and Reuse Technology in India
}

\author{
Dr. G. Taviti Naidu ${ }^{1}$, Seepana Kiran Kumar ${ }^{2}$ \\ ${ }^{1}$ Post Doctoral Fellow, DCMS, Andhra University, Visakhapatnam, AP, India \\ dr.tavitinaidugongada@gmail.com \\ ${ }^{2}$ Student, Andhra University, Visakhapatnam, AP, India
}

\begin{abstract}
Water is one of the most essential natural resources for sustaining life. Its development and management play a vital role in agriculture production. Integrated water management is vital for poverty reduction, environmental sustenance, and sustainable economic development. Because of the rapid increase in population, urbanization, and industrialization, the demand for water for meeting various requirements is continuously increasing. Therefore, we are facing numerous challenges in the water sector. The last few decades have seen a dramatic rise in the demand for water in India due to a variety of socio - economic processes and demographic trends. Supplies have also grown manifold, to keep pace with the demand through the exploitation of surface and groundwater. The result: groundwater resources are over - exploited in many arid and semiarid regions, leading to falling water levels, deteriorating groundwater quality causing groundwater scarcity
\end{abstract}

Keywords: Water management, Urine, Recycling, $\mathrm{H} 2 \mathrm{O}$ purifier

\section{Introduction}

Water is essential to human life. In fact, since 60 percent of the human body is water, it can be said that water is life itself. Without water, no field of human activity can be complete. Today, the world is debating if the flow of information is more important than the flow of energy. That is a good question. But the flow of water is still more important. It is fundamental to the economy and ecology and human equity. The issue of water is becoming still more critical because of climate change and related environmental concerns. Water is central to some of the flagship programs in India. The modernization of India may be largely dependent on the modernization of its water management. This is not surprising since India supports 17 percent of the global population but has only 4 percent of the world's water resources. Better and more efficient use of water is a challenge for Indian agriculture and industry alike. It requires to set new benchmarks in both villages and the cities. In India, 54 percent of the people are dependent on farming for their livelihood. Yet, their share of national income is only 14 percent. To make agriculture more remunerative and to improve the prosperity of farming communities, the Indian government has introduced many new projects. These include:

1) The Centre has set a target of providing clean drinking water to all by 2024. The government has announced an ambitious target of providing piped clean drinking water to all rural households by 2024 .

2) 'Doubling Farm Incomes by 2022': To achieve this, the Indian government is rapidly expanding the area under irrigation, and completing 99 long - pending irrigation projects. Sixty percent of these projects are in drought prone areas.

Under the 'Make in India' mission, India is working to sharply increase the share of manufacturing in its GDP. From the current 17 percent of GDP, efforts are being made to take it to 25 percent by 2025 . Industry requires a large volume of water. This is particularly true for the manufacture of electronic hardware, computers, and mobile phones. And these are all focus areas for 'Make in India'.

Currently, 80 percent of water in India is used by agriculture and only 15 percent by industry. In the coming years, this ratio may change. The total demand for water will also rise. The efficiency of water use and reuse, therefore, has to be built into the blueprint of industrial projects. Business and industry need to be a part of the solution. India is urbanizing at a rate not seen in its history. An effort is being made to build or upgrade 100 modern cities as part of the Smart Cities initiative. Reuse of water, solid waste management and better sanitation infrastructure and practices are benchmarks to assess Smart Cities. In urban India, 40 billion liters of wastewater are produced every day. It is vital to adopt technology to reduce the toxic content of this water, and to deploy it for irrigation and other purposes. This has to be part of any urban planning program.

\section{Review of Literature}

An article was published in Hindu newspaper that elaborates about the designs by the students of IIT - M to recycle urine for different uses but the aim is to recycle urine into freshwater, then go to a different article about water management method and reproduce of water there are many methods for example some countries in the world constructed a plant which is used for convert ocean water into drinking water it is highly expensive and need more control of plant management then I gone through groundwater management is an old method but it will give better result but lake of land in cities it is more difficult in present metropolitan cities then best suitable is convert urine into drinking water it is easy to collect urine from a public place and pipeline facilities provide by government and we placed the plant in a certain place and supply the water for home and wastewater is can use agriculture and by adding some impurities to the water 
Majorly, we are facing water scarcity in India because of a lack of awareness. In India metropolitan cities are in cries condition especially Mumbai, Delhi, Hyderabad \& Chennai which are facing water problems in summer because the underground water table has gone down drastically.

\section{Water Related Problems in India in 2019}

Chennai is dealing with a crippling crisis: It has run out of water. Particularly, in the middle of the hot summer, the four lakes that supply the capital of the southern state of Tamil Nadu have dried up; together they contain just 1 percent of the volume they did last year. Residents don't have enough water to drink, bathe or wash clothes. People are working from home; malls have closed their bathrooms, and restaurants have shut their doors.

According to the Composite Water Management Index (CWMI) report released by the Niti Aayog in 2018, 21 major cities (Delhi, Bengaluru, Chennai, Hyderabad, and others) are racing to reach zero groundwater levels by 2020 , affecting access for 100 million people.

World Bank is supporting India's efforts to better manage its water resources. For better water management the activities are classified into six broad categories:

1) Providing Drinking Water to Rural Areas

2) Groundwater management

3) Improving access to water on dry rainfed lands

4) Cleaning the Ganga

5) Managing Floods and Droughts

6) Enhancing Dam Safety in India

\section{Also, we need to make reproduce of water for the needs} Converting Urine into Purified Water

\section{Concept of purifying urine by solar powered machine} Using solar power machines we can recycle urine into drinking water. And this can be used to make beer. At first, urine is collected in a tank and heat it in a solar - powered still. The nutrients get separated as it passed through the membrane, and the separated nutrients can be used as fertilizer in the agricultural field as it contains nitrogen and phosphorus.

Astronauts on the international space stations are purifying and drinking their urine since 2008 by the process of osmosis. In this process, there are two containers of liquid separated by a membrane. One is urine and the other is the sugary solution. Through osmosis water in urine flow through the membrane to the sugary solution leaving behind the solute and urea.

H2O PURIFIER The concept of urine purification into drinking water by the $\mathrm{H} 2 \mathrm{O}$ purifier was put forward by designer Leonardo Manavella. It is used in emergencies and areas where unsafe water is using. When users urinate on the activated carbon in the purifier, the color and flavor are eliminated. The water is ready to drink on squeezing the container

\section{Conclusion}

The water management challenges India is facing today are great. First of all, wide gaps exist in our understanding of physical problems and management solutions. Management solutions that are technically and economically feasible and socially and politically viable are not forthcoming. Over and above, the government policies and programmers are largely tuned to develop water resources rather than manage it. The no availability of adequate scientific information regarding availability and quality of water, demand for water in different sectors, nature and extent and causes of water problems become major hindrances to developing sustainable water management strategies. The root of the problem also lies in the lack of coordination among agencies for data collection, 20 processing and retrieval, and the lack of integration of social, economic and environmental factors in the assessment of resource condition.

Technology is another major challenge. Technologies available for water conservation and management are limited and less popular. Advancements in water technology aimed at evolving technically feasible, economically viable, environmentally and ecologically sound and socially acceptable solutions in water management are not occurring.

\section{References}

[1] http: //jalshakti - dowr. gov. in/programmes/central water - and - power - research - station

[2] https: //www.worldbank. org/en/news/feature/2019/03/22/helping - india manage - its - complex - water - resources

[3] https: //economictimes. indiatimes. com/news/economy/policy/government - sets - target of - providing - clean - drinking - water - to - all - by 2024/articleshow/69741109. $\mathrm{cms}$ ?from $=\mathrm{mdr}$ 